\title{
A Possible Hypoallergenic Cereal in Wheat Food Allergy and Baker's Asthma
}

\author{
Alicia Armentia ${ }^{1 \#}$, Sara Martín², Araceli Diaz-Perales ${ }^{3}$, Arantxa Palacín ${ }^{3}$, Leticia Tordesillas ${ }^{3}$, \\ Manuel Herrero ${ }^{1}$, Blanca Martín-Armentia ${ }^{1}$ \\ ${ }^{1}$ Allergy Section, IEN, UMDAI, Hospital Universitario Rio Hortega de Valladolid, Valladolid, Spain; ${ }^{2}$ Pediatrics Service, Hospital \\ Universitario Rio Hortega, Valladolid, Spain; ${ }^{3}$ Departamento de Biotecnología, ETS Ingenieros Agrónomos, Madrid, Spain. \\ Email: *aliciaarmentia@gmail.com
}

Received September $9^{\text {th }}, 2012$; revised October $12^{\text {th }}, 2012$; accepted November $14^{\text {th }}, 2012$

\begin{abstract}
Background: Wheat is a potent allergen source and is one of the causes of baker's asthma and food allergy. The best strategy for managing food hypersensitivity involves strict avoidance of the trigger. However, wheat is quite difficult to avoid. Several alternative strategies for the treatment of food allergy are under study. Spelt is a possible hypoallergenic crop that may be tried in patients with wheat allergy. Methods: We have evaluated the allergenic IgE hypersensitivity mediated by spelt in wheat allergic patients. Overall, 66 patients who suffered from baker's asthma or food allergy (45 males and 21 females, mean age $28.6 \pm 12.9$ years) were included. We have also compared its reactivity with standardized extracts from wheat and with purified non-specific lipid transfer proteins from wheat (Tri a 14) and from peach (Pru p 3). Immunodetection with spelt and common bread wheat extracts (Triticum aestivum, cultivar Astral) was performed. Fresh wheat and spelt grain extracts were used both for oral and bronchial challenge and skin tests. Specific IgE detection to different cereals was performed using the Immuno CAP System (Phadia, Uppsala, Sweden). The bronchial challenge was positive with wheat Astral in 44 (67\%) patients, all of them suffered from asthma. Thirteen (29.54\%) of these 44 patients had negative the challenge with spelt. The oral challenge with wheat Astral was positive in 22 (33\%) patients with wheat food allergy, and the same test was positive in only in 6 of them with spelt (27.3\%). The diagnostic yield (sensitivity, specificity and predictive values) of routine tests in determining spelt allergy by specific positive challenge responses was determined. Prick tests for spelt versus positive challenge tests had a good sensitivity ( $94 \%$, 86.5 - 99.4; 95\% CI) and specificity (86\%, 84 - 90; 95\% CI) for the diagnosis of spelt allergy. Immunodetection detected minor differences among different extracts. Conclusion: In summary, the prick test and bronchial and oral challenges both efficiently detected sensitization to spelt and their levels were related to more severe clinical profiles, but the wheal area was significantly lower with spelt $(\mathrm{p}<0.001)$ and the percentage of positive challenge tests decreased. Our results suggest that spelt is an old crop that may be tried in patients with wheat allergy.
\end{abstract}

Keywords: Spelt; Wheat Allergy; Food Allergy; Low Allergenic Plant Culture

\section{Introduction}

Wheat is a potent allergen source and is one of the causes of baker's asthma and food allergy [1,2]. The best strategy for managing food hypersensitivity involves strict avoidance of the trigger. However, wheat is quite difficult to avoid. Aside from being an ingredient in many foods, it is used in the formation of drug's pills, as a glaze and thickener, a stabilizer, a bulking agent, an emulsifier, a binder, and a starch.

Some strategies have been used successfully in producing cultivars of soybeans and peanuts with reduced allergenic proteins [3].

\footnotetext{
*This manuscript has not conflict of interest.

\#Corresponding author.
}

Spelt, also known as Dinkel, is an early form of wheat, originated near the Caspian Sea.

Common in the Iron Age and early Roman Period, it was later replaced for bread making by wheat which is easier to thresh from the earth.

\section{Case Presentation}

During the past years we have purified and characterized several proteins from bread-wheat associated with flour allergy [4]. Now we have evaluated the allergenic IgE hypersensitivity mediated by spelt in wheat allergic patients. We have also compared its reactivity with standardized extracts from wheat and with purified nonspecific lipid transfer proteins from wheat (Tri a 14) and 
from peach (Pru p 3). Immunodetection with spelt and common bread wheat extracts (Triticum aestivum, cultivar Astral) was performed.

Wheat allergy patients were selected from a data base of 21,582 patients. Controls were 100 non-atopic blood donors. All participants gave informed consent. Overall, 66 patients who suffered from baker's asthma or food allergy (45 males and 21 females, mean age $28.6 \pm 12.9$ years) were included. The protocol was approved by the hospital Clinical Research Ethics Committee.

Fresh wheat and spelt grain extracts (both $5 \mathrm{mg}$ protein $/ \mathrm{ml}$ ) were used both for oral and bronchial challenge and skin tests. Specific IgE detection to different cereals was performed using the ImmunoCAP System (Phadia, Uppsala, Sweden).

The bronchial challenge was positive with wheat Astral in $44(67 \%)$ patients, all of them suffered from asthma. Thirteen (29.54\%) of these 44 patients had negative the challenge with spelt. The oral challenge with wheat Astral was positive in 22 (33\%) patients with wheat food allergy, and the same test was positive in only in 6 of them with spelt (27.3\%).

The diagnostic yield (sensitivity, specificity and predictive values) of routine tests in determining spelt allergy by specific positive challenge responses was de-
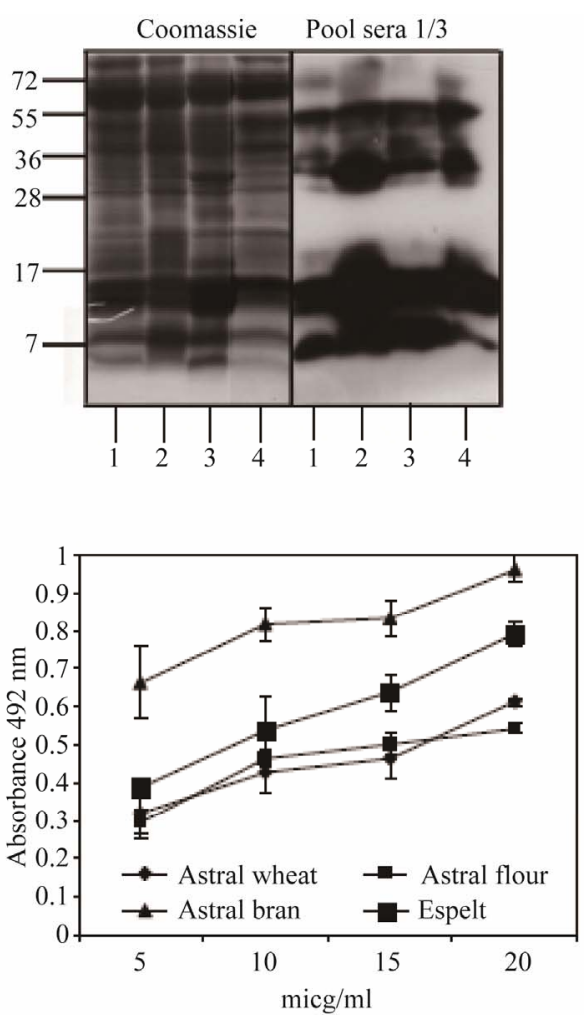

termined. Prick tests for spelt versus positive challenge tests had a good sensitivity (94\%, 86.5 - 99.4; 95\% CI) and specificity (86\%, 84 - 90; 95\% CI) for the diagnosis of spelt allergy. Immunodetection detected minor differences among different extracts (Figure 1). Apparently the LTP (Tri a 14) response was decreased, although previous report involved LTP reactivity in spelt [5].

\section{Discussion}

Several alternative strategies for the treatment of food allergy are under study. Developing a selection of low allergenic plant cultures, removing allergens by genetic modification, and new food processing methods are possibilities to lessen cases [3,4].

However, it is unknown whether the cultivars are actually hypoallergenic to those with sensitivity. Spelt is now grown in small quantities in Europe and America for the health food market, and used for bread making, processed into flakes for muesli, or roasted as a "coffee" substitute. In our patients, the prick test and bronchial and oral challenges both efficiently detected sensitization to spelt and their levels were related to more severe clinical profiles, but the wheal area was significantly lower with spelt $(\mathrm{p}<0.001)$ and the percentage of positive challenge tests decreased.

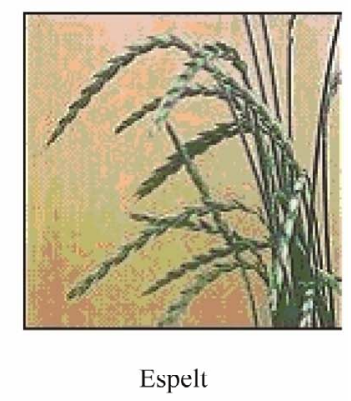

Figure 1. IgE reactivity of whole hexaploid wheat astral, only flour, only bran and spelt in immunodetection using sera pools of patients and controls. Apparently the LTP (Tria a 14) response was decreased although the protein quantification was similar. Line 1: Triticum aestivum, cultivar Astral whole extract; Line 2: Triticum aestivum, cultivar Astral flour extract; Line 3: Triticum aestivum, cultivar Astral bran extract; Line 4: whole espelt (Triticum aestivum subsp. espelta) extract. 


\section{Conclusion}

Our results suggest that spelt is an old crop that may be tried in patients with wheat allergy, after allergic tests with this cereal.

\section{Acknowledgements}

We thank all the participants, especially the patients, for their courage and interest. They deserve our best efforts. The authors also thank Antonio y Andrés Solanot for his agricultural assistance and production of spelt used in the study.

\section{Declaration of All Sources of Funding}

This work was subsidized by the General Direction of Public Health, Research, Innovation and Development, Sanidad Castilla y León. (SACYL) and registered in its data base GRS 446/A/10.

\section{REFERENCES}

[1] A. Tordesillas, A. Diez Perales, A. Armentia, L. Pacios and G. Salcedo, "Molecular Basis of Allergen Cross-Reactivity: Non-Specific Lipid Transfer Proteins from Wheat Flour and Peach Fruit as Models," Molecular Immunol- ogy, Vol. 47, No. 2-3, 2009, pp. 534-540. doi:10.1016/j.molimm.2009.07.028

[2] L. Zuidmeer, K. Goldhahn, R. J. Rona, D. Gislason, C. Madsen, C. Summers, E. Sodergren, J. Dahlstrom, T. Lindner, S. T. Sigurdardottir, D. Mc Bride and T. Keil, "The Prevalence of Plant Food Allergies: A Systematic Review," Journal of Allergy and Clinical Immunology, Vol. 121, No. 5, 2008, pp. 1210-1218. doi:10.1016/j.jaci.2008.02.019

[3] J. J. Riascos, A. K. Weissinger, S. M. Weissinger and A. W. Burks, "Hypoallergenic Legume Crops and Food Allergy: Factors Affecting Feasibility and Risk," Journal of Agricultural and Food Chemistry, Vol. 58, No. 2, 2010, pp. 20-27. doi:10.1021/jf902526y

[4] M. De Gregorio, A. Armentia, A. Diaz-Perales, A. Palacín, A. Dueñas-Laita, B. Martín, G. Salcedo and R. Sánchez-Monge, "Salt Soluble Proteins from Wheat-Derived Foodstuffs Show Lower Allergenic Potency than Those from Raw Flour," Journal of Agricultural and Food Chemistry, Vol. 57, No. 8, 2009, pp. 3325-3330. doi:10.1021/jf803475v

[5] E. A. Pastorello, L. Fariolo, A. M. Robino, C. Trambaioli, A. Conti and V. Pravettoni, "A Lipid Transfer Protein Involved in Occupational Senstization to Spelt,” Journal of Allergy and Clinical Immunology, Vol. 108, 2001, pp. 145-146. 